\title{
The short half-life of glucagon-like peptide-1 in plasma does not reflect its long-lasting beneficial effects
}

\author{
Hongxiang Hui ${ }^{1}$, Loredana Farilla ${ }^{1}$, Patricia Merkel $^{1}$ and Riccardo Perfetti ${ }^{1,2}$ \\ ${ }^{1}$ Division of Endocrinology and Metabolism, Cedars-Sinai Medical Center and ${ }^{2}$ University of California, Los Angeles, California, USA \\ (Correspondence should be addressed to R Perfetti, Division of Endocrinology and Metabolism, Cedars-Sinai Medical Center, 8723 Alden Drive, \\ SSB \#290, Los Angeles, California 90048, USA; Email: perfettir@cshs.org)
}

\begin{abstract}
The incretin hormone glucagon-like peptide-1 (GLP-1) is capable of ameliorating glucose-dependent insulin secretion in subjects with diabetes. However, its very short half-life (1.5-5 min) in plasma represents a major limitation for its use in the clinical setting. The present study was designed to characterize the duration of the effect of GLP-1 in the Zucker diabetic fatty (ZDF) rat. ZDF rats were subjected to a $48 \mathrm{~h}$ infusion of human GLP-1 (30 pmol/kg per min), followed by an i.p. glucose tolerance test (IPGTT) ( $1 \mathrm{~g} / \mathrm{kg}$ body weight), $2 \mathrm{~h}$ after removing the infusion pump. At $15 \mathrm{~min}$ from the beginning of the test, GLP-1-treated animals had lower plasma glucose levels $(442 \pm 38 \mathrm{mg} / \mathrm{dl})$ than salineinfused controls $(583 \pm 63 \mathrm{mg} / \mathrm{dl}, P<0.01)$. This was reflected in the higher insulin levels attained in the GLP-1-treated animals (1999 \pm 163 vs $1250 \pm 51 \mathrm{pmol} / \mathrm{l}$, GLP-1 vs saline respectively, $P<0.01$ ). Repetition of the IPGTT on day 3, 9 and 16 from the removal of the infusion pump revealed a surprising lasting 'memory' of the exposure to GLP-1. Indeed, the best insulin secretory response was observed approximately 1 week after discontinuation of the GLP-1 infusion, and lasted up to 3 weeks from the early exposure to GLP-1. Detection of fasting plasma levels of GLP-1 during the 3 weeks of the experiment showed a very rapid decline, consistent with the data reported by others. Our findings provide evidence for a long-lasting beneficial effect of GLP-1 that persists for weeks even when the circulating levels of GLP-1 are back to normal.
\end{abstract}

European Journal of Endocrinology 146 863-869

\section{Introduction}

Glucagon-like peptide-1 (GLP-1) is a 30 amino acid peptide secreted from the L-cells of the intestinal epithelium in response to food. GLP-1 is formed as a result of proteolytic cleavage of proglucagon (1). It is the most potent insulinotropic hormone known $(2,3)$. GLP-1 action is mediated by its binding to a cell-surface receptor. This belongs to the secretin/ glucagon superfamily receptors that are coupled to heterotrimeric G proteins. Binding of GLP-1 to its receptor stimulates cAMP formation and a rise in intracellular $\mathrm{Ca}^{2+}$. Interestingly, the insulinotropic activity of GLP-1 is retained in patients with diabetes, even after many years from the diagnosis (4). Indeed, after administration of i.v. GLP-1, the insulin secretory response in non-diabetic and diabetic subjects is remarkably similar (5). When administered by i.v. injection for $4 \mathrm{~h}$ to subjects with type 2 diabetes, whose fasting blood glucose was poorly controlled on diet and sulfonylurea therapy, GLP-1 normalized the fasting and postprandial glucose levels $(6,7)$. These observations suggest that even if $\beta$-cells of the pancreas no longer respond to sulfonylureas, GLP-1 therapy may still be an option for the treatment of type 2 diabetes.

The major drawback for the use of GLP-1 in the clinical setting is its short biological half-life $(1.5-5 \mathrm{~min})$. Even when given s.c. its peak concentrations have returned to baseline by $90 \mathrm{~min}(1,3,8,9)$. However, when GLP-1 is given continuously to subjects with type 2 diabetes, blood glucose is normalized and, more importantly, postprandial glucose excursions are also blunted (6). The present study was undertaken to assess the duration of the glucose-normalizing effect of GLP-1 in an animal model of type 2 diabetes after a $48 \mathrm{~h}$ constant infusion. Using Zucker diabetic fatty (ZDF) rats, we demonstrated that although GLP-1 levels in rat plasma rapidly return to normal after discontinuation of a continuous infusion, its beneficial effect in enhancing glucose-dependent insulin secretion lasts for weeks. 


\section{Materials and methods}

\section{Animals}

Twelve-week-old male ZDF rats, as well as age- and sexmatched Zucker lean control (ZLC) rats were purchased from Harlan Bioproducts for Science, Inc. (Indianapolis, IN, USA) and maintained on standard laboratory chow under a $12 \mathrm{~h}$ light:12 h darkness schedule. They were given free access to food and water until the evening before any experimental procedure, when food was removed. All institutional guidelines for care and use of animals were followed.

\section{Protocols}

Insulin secretory response in $\mathrm{ZDF}$ and $\mathrm{ZLC}$ rats ZDF and ZLC rats were subjected to an i.p. glucose tolerance test (IPGTT) (1 g glucose/kg body weight) after an overnight fast ( $n=5$ per group). Glucose was administered as a single bolus injection that lasted $1 \mathrm{~min}$. Blood samples were collected by tail vein incision at $-20,2,15,30,45,60,90$ and $120 \mathrm{~min}$ from the beginning of the infusion. This procedure allowed for collection without cutting the skeletal component of the tail and did not require the catheterization of a blood vessel. Blood samples were then assayed for glucose and insulin levels.

Dose response to GLP-1 To determine the dose response to GLP-1, ZDF rats were subject to a 2 day infusion of different concentrations of human recombinant GLP-1 (Bachem, King of Prussia, PA, USA). Four rats per treatment group (saline; $1.5 \mathrm{pmol} / \mathrm{kg}$ per $\mathrm{min} ; 15 \mathrm{pmol} / \mathrm{kg}$ per $\mathrm{min} ; 30 \mathrm{pmol} / \mathrm{kg}$ per $\mathrm{min}$ ) were used. The infusion of GLP-1 was performed using an Alzet micro-osmotic pump (Alza Corp., Minneapolis, MN, USA) implanted in the interscapular region for $48 \mathrm{~h}$. Prior to the surgical implant of the pump, the rats were anesthetized using $45 \mathrm{mg} / \mathrm{kg}$ ketamine (Phoenix Scientific, Inc., St Joseph, MO, USA) and $4.5 \mathrm{mg} / \mathrm{kg}$ xylazine (Loyd Laboratories, Shenandoah, IO, USA). Two hours after the removal of the infusion pump they were subjected to an IPGTT, as described above, and blood samples were collected.

Effect of GLP-1 infusion in ZLC and ZDF rats To evaluate the efficacy of GLP-1, ZDF and ZLC rats ( $n=6$ per treatment group) were subjected to a $48 \mathrm{~h}$ infusion with GLP-1 (30 pmol/kg per min) or saline solution, and tested for insulin and glucose levels through an IPGGT, as described above.

Duration of GLP-1 effect on the glucose-dependent secretion of insulin After determining the optimal dose of GLP-1 to elicit the maximal insulin secretory response, ZDF rats were subjected to repetitive IPGTT at $1,3,9$ and 16 days after removal of the infusion pump ( $n=6$ per treatment group). Each individual rat was subjected to repetitive IPGTTs (after an overnight fast), and the insulin secretory response was compared.

\section{Assays}

Insulin and GLP-1 plasma levels were measured by RIA (Linco Research, Inc., St Charles, MA, USA). The GLP-1 kit specifically recognized the active ( $7-36$ amide) GLP-1. Plasma glucose was measured by the glucose oxidase method. The areas under the curve (AUCs) for insulin and glucose were calculated according to the trapezoidal rule from insulin measurements at baseline, 2, 15 and $30 \mathrm{~min}$.

\section{Statistical analysis}

The data are expressed as means \pm s.E. Significance of the data was evaluated by an unpaired Student's $t$-test. One-way ANOVA was used to evaluate statistical significance when more than two data points were analyzed. Statistical analyses by unpaired Student's $t$-test or ANOVA are explicitly identified in the text or in the figure legends.

\section{Results}

\section{Glucose tolerance in ZLC and ZDF rats}

There was a significant difference in the fasting serum glucose $(260 \pm 26.1$ vs $106 \pm 9.2 \mathrm{mg} / \mathrm{dl}$, ZDF vs ZLC respectively; $P<0.001)$ or insulin $(925 \pm 89.6$ vs $364 \pm 66.4 \mathrm{pmol} / \mathrm{l}$, ZDF vs ZLC respectively; $P<0.001$ ) between ZDF and ZLC rats.

After an IPGTT, the secretion of insulin was increased significantly in both the ZLC and ZDF rats. However, while the ZLC rats exhibited a brisk peak at $15 \mathrm{~min}$ and had their insulin level returning back to baseline at $45 \mathrm{~min}$, the ZDF rats showed a delayed and prolonged insulin secretory response, returning to baseline only after $2 \mathrm{~h}$ from the beginning of glucose infusion (Fig. 1). The increased baseline insulin level together with the abnormal kinetics of insulin secretion observed in the ZDF rats resulted in much greater insulin levels over the time period of the IPGTT. The AUC calculated from the injection of glucose to the end of the test $(120 \mathrm{~min})$ showed that ZDF rats had a 4.5-fold increase in insulin levels, when compared with ZLC control rats $(P<0.001)$ (Fig. 1).

Glucose levels in the two animal groups showed a variation that was opposite to the one observed for insulin. As expected, after an IPGTT the glucose levels of ZDF rats increased to a much greater extent and for a longer period of time when compared with ZLC rats (Fig. 1). The AUC for glucose from 2 to $30 \mathrm{~min}$ from the beginning of the test showed a 3.7-fold greater glucose level in $\mathrm{ZDF}$ rats compared with ZLC $(P<$ $0.001)$. 

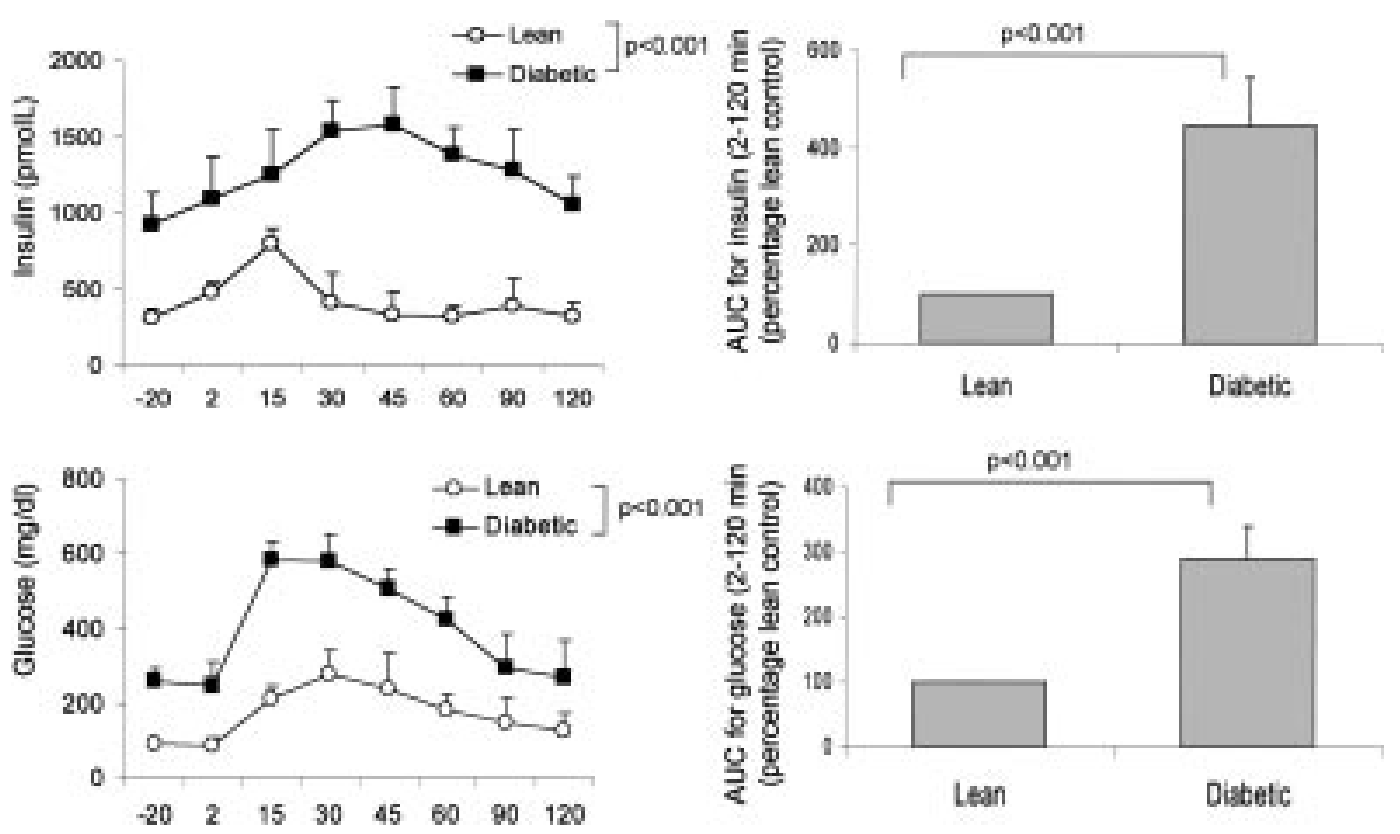

Figure 1 Insulin and glucose responses (means \pm S.E., $n=6$ ) of ZDF and ZLC rats after an IPGTT. Panels on the left depict insulin (top) and glucose (bottom) responses after an IPGTT with $1 \mathrm{~g}$ of glucose $/ \mathrm{kg}$ body weight, in ZDF and ZLC rats. Statistical significance was evaluated by ANOVA. Panels on the right represent the AUC for insulin (top) and glucose (bottom) after an IPGTT with $1 \mathrm{~g}$ of glucose/kg body weight, in the same animal groups shown in the panels on the left. The AUC was generated using the time points between 2 and $120 \mathrm{~min}$ after the injection of glucose. Statistical significance of the data was evaluated by Student's $t$-test.

\section{GLP-1 dose-dependent response after IPGTT}

ZLC and ZDF rats showed a different threshold of response to a $48 \mathrm{~h}$ infusion of GLP-1. While ZLC rats exhibited their maximum insulin secretory response with $1.5 \mathrm{pmol}$ GLP-1/kg per min $(P<0.01$, GLP-1treated vs saline-infused rats), the minimum dose of GLP-1 capable of eliciting an increase in insulin secretion in ZDF rats was 10 -fold greater $(15 \mathrm{pmol} / \mathrm{kg}$ per min) $(P<0.01$ for GLP-1-treated vs saline-infused rats), and it was best when they were subjected to the infusion of $30 \mathrm{pmol} / \mathrm{kg}$ per min of GLP-1 $(P<0.001$, GLP-1-treated vs saline-infused rats). Figure 2 shows the AUC for insulin and glucose $(2-30 \mathrm{~min})$ of $\mathrm{ZDF}$ rats infused with increasing concentrations of GLP-1.

\section{GLP-1 enhances glucose tolerance in ZDF rats}

The infusion of GLP-1 had a significantly positive effect on both glucose excursion and insulin secretion, both in ZDF and in ZLC rats (Fig. 3). This occurred by respectively increasing and decreasing the AUC for insulin and glucose within the first $30 \mathrm{~min}$ from the beginning of glucose infusion. In ZDF rats, GLP-1 partially restored the early-phase insulin secretion peak, characteristically lost in subjects with diabetes, and it was also capable of rapidly lowering plasma insulin levels after the initial secretory spike that occurred within the first $15 \mathrm{~min}$ from the beginning of the test $(P<0.05$, GLP-1 vs saline-treated rats) (Fig. 3).

\section{Prolonged amelioration of glucose tolerance in GLP-1-treated ZDF rats}

ZDF (30 pmol/kg per min) and ZLC (1.5 pmol/kg per min) rats were subjected to IPGTTs multiple times after the discontinuation of the GLP-1 infusion. The first IPGTT was performed 1 day after the end of the infusion (day 1) and the test was repeated, in the same rats, at day 3 , day 9 and day 16 . We observed that after the first IPGGT, the GLP-1-dependent amelioration in glucose tolerance, rather than declining, got progressively better, and reached its very best at day 9. Indeed, while glucose excursions were progressively less vigorous over time, the bursts of insulin secretion in response to the exogenous administration of glucose got progressively better as the number of days from the GLP-1 infusion increased (Fig. 4). Even on day 16, when the effect of GLP-1 probably started to decline, treated rats had a much better response to glucose than control saline-treated rats.

Repetitive measurements of plasma GLP-1 levels in the fasting state did not show a significant variation over the 3 week period of the study (Fig. 5). This confirmed the data reported by various studies that GLP-1, when administered exogenously, is rapidly eliminated from the blood stream and also demonstrated that the exogenous GLP-1 did not induce an upregulation of the endogenous GLP-1 levels. 

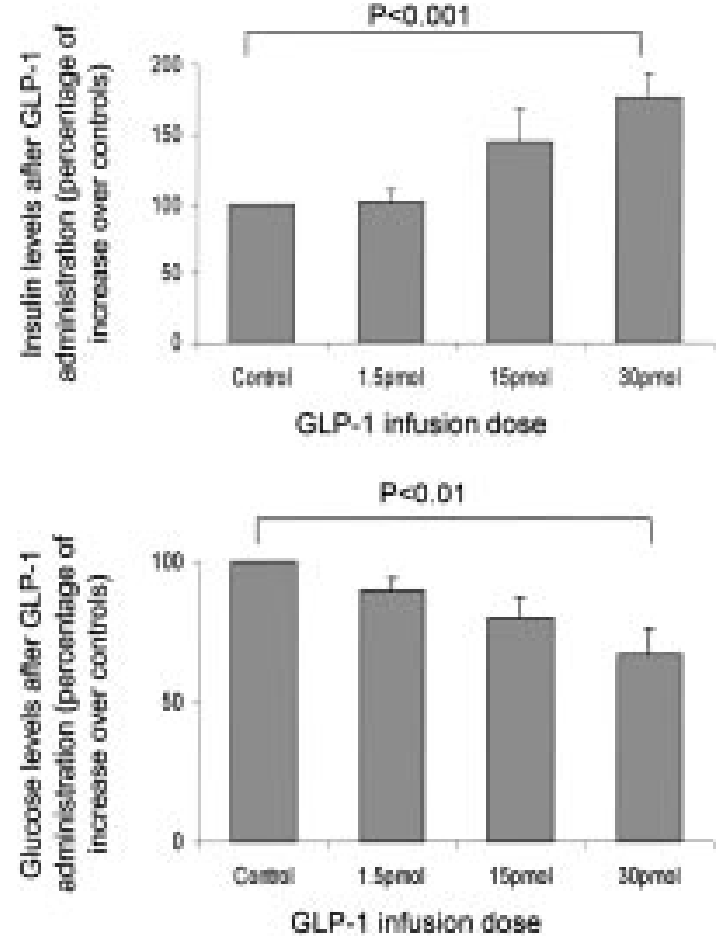

Figure 2 Dose-dependent response to GLP-1 of ZDF rats after an IPGTT. Insulin (top panel) and glucose (bottom panel) levels were evaluated after an IPGTT with $1 \mathrm{~g}$ glucose $/ \mathrm{kg}$ body weight. AUCs from 2 to $30 \mathrm{~min}$ from the glucose injection were evaluated for glucose and insulin. AUCs determined in control rats (salineinfused) were considered as equal to $100 \%$ and the responses to various doses of GLP-1 were calculated as percentages (means \pm S.E., $n=6$ ) of controls. Statistical significance was evaluated by Student's $t$-test.

\section{Changes in body weight in GLP-1-treated rats}

GLP-1 has a well known effect on the inhibition of satiety. In the present study we observed a significant reduction in body weight, both in ZDF and in ZLC rats, following the infusion of GLP-1 $(P<0.001$ and $P<0.05$ in ZDF and ZLC rats respectively) (Table 1). This decrease in weight reached its peak after 6 days from the discontinuation of the treatment with GLP-1, and remained stable in the last week of the study.

\section{Discussion}

The capability of GLP-1 to stimulate insulin secretion depends on the concentration of its active form (GLP$1(7-36))$ in the blood stream. The plasma level of GLP-1 is regulated by its rate of production, due to synthesis and secretion by the L-cell of the gastrointestinal tract $(1,3,10)$, and by the rate of disappearance from the blood stream, resulting from its enzymatic degradation (1.5-2 min) (10) and the renal clearance (12 min) $(10,11)$. The chief regulatory mechanism employed for the control of the concentration of active GLP-1 is represented by its rate of degradation.
The enzyme dipeptidyl peptidase IV (DPP IV), which is present in the plasma and in tissues, is the primary, although not the exclusive, inactivating enzyme for GLP-1 (12). DPP IV can liberate Xaa-Pro or Xaa-Ala dipeptides from the N-terminus of regulatory peptides. The enzymatic digestion of GLP-1 generates many metabolites, including GLP-1(9-36), GLP-1(7-35), GLP-1(7-34) and GLP-1(9-36) amides (13). None of these are capable of promoting insulin secretion, and in pharmacological concentrations they are thought to act as antagonists of the active form of GLP-1. The importance of the kidney in the clearance of GLP-1 involves both the glomerular filtration rate and the tubular catabolism. It has been shown that 10 min after the injection of radiolabeled GLP-1, the major part of the radioactivity is accumulated in the kidney (14).

In this study, we confirmed that GLP-1 potentates glucose-stimulated insulin secretion in vivo. A dosedependent response to GLP-1 of non-anesthetized ZDF rats was observed after an IPGTT. Compared with saline-infused ZDF rats, a $48 \mathrm{~h}$ infusion with GLP-1 produced a significant dose-dependent increase in insulin secretion and lowering of glucose excursion after a glucose challenge.

In human subjects, not affected by diabetes, a GLP-1 dose-response study has revealed that a rapid s.c. administration of $0.5 \mathrm{nmol} / \mathrm{kg}$ GLP-1 represents the threshold dose for a minimum stimulation of glucosedependent insulin secretion (15). In non-diabetic mice and rats, the threshold level of GLP-1 capable of eliciting insulin secretion has been reported to be between 0.3 and $0.5 \mathrm{nmol} / \mathrm{kg}$, with a half-maximal effect observed with $1 \mathrm{nmol} / \mathrm{kg}$ (16-18). In the present study, we demonstrated that a constant infusion of $1.5 \mathrm{pmol} / \mathrm{kg}$ per min of GLP- 1 for $48 \mathrm{~h}$ was not sufficient to increase the secretion of insulin in ZDF rats, and that the earliest significant response to GLP-1 was observed when its concentration was raised 10fold (15 pmol/kg per min).

While the observation that GLP-1 is effective in lowering plasma glucose levels in ZDF rats confirms the work of others $(19,20)$ the novelty of the present study is represented by the demonstration that although GLP-1 is rapidly degraded and removed from the blood stream, its beneficial effect lasts for days after its administration.

Pharmacokinetic studies of exogenously administered GLP-1 demonstrate its rapid elimination from the plasma, with a half-life of $3.3 \pm 0.6 \mathrm{~min}$, a clearance of $117 \pm 15 \mathrm{ml} / \mathrm{min}$, and a distribution volume of $557 \pm$ $61 \mathrm{ml}$ (14). In the present study, repetition of an IPGTT in diabetic animals over time showed a surprisingly lasting beneficial effect of an earlier exposure to GLP-1. Interestingly, the best glucose-dependent insulin secretory response was observed 9 days after the GLP-1 infusion pump was removed from the diabetic animals. This finding is in evident contradiction to the general understanding of the time of action of GLP-1. However, 

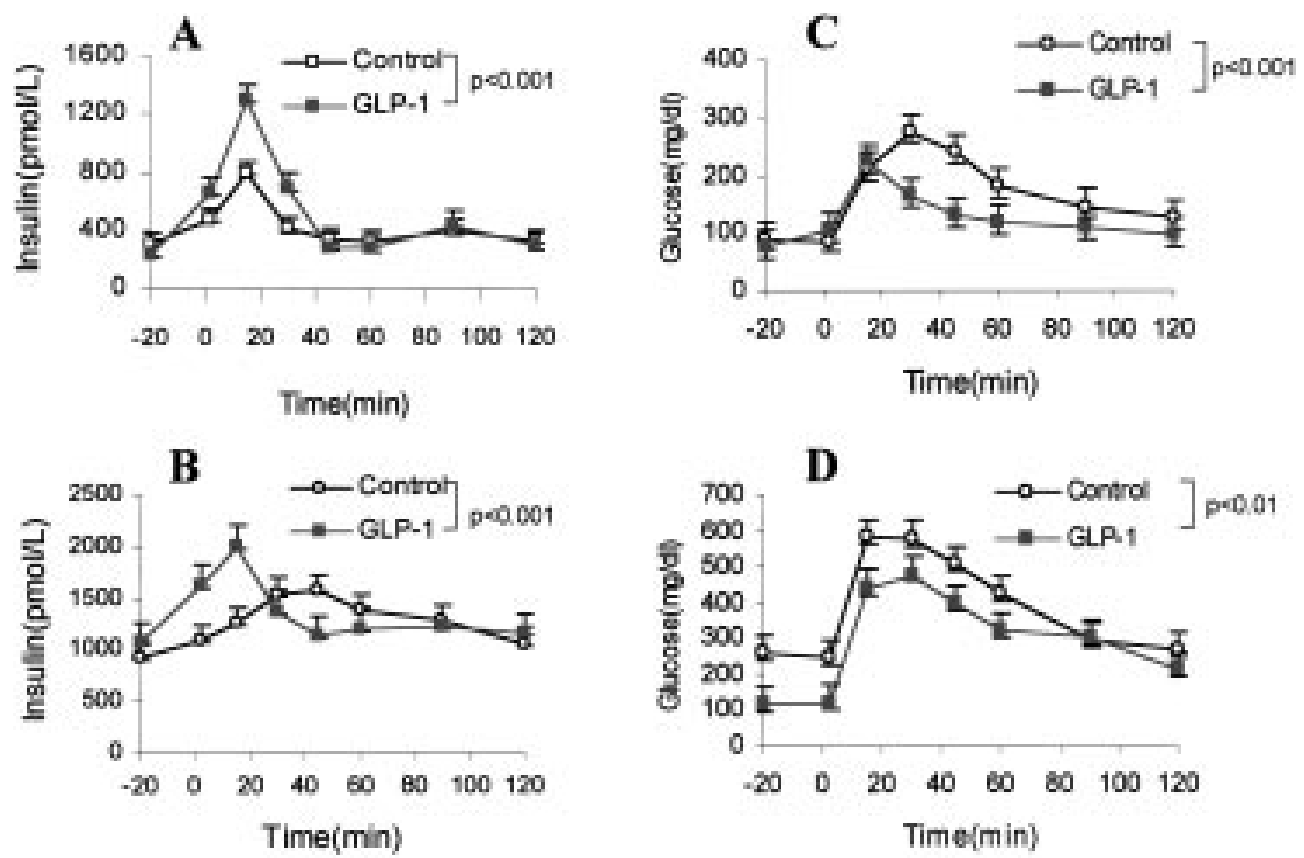

Figure 3 Insulin and glucose responses (means \pm S.E., $n=6$ ) of GLP-1-treated ZDF and ZLC rats after an IPGTT. Insulin (A, B) and glucose (C, D) levels were evaluated by subjecting ZLC (A, C) and ZDF (B, D) rats to an IPGTT (1 g/kg body weight) after a $48 \mathrm{~h}$ infusion with GLP-1 (30 pmol/kg per min) or saline solution. Statistical significance was evaluated by ANOVA.

a careful review of previous studies appears to support, indirectly, the data of our current report. Burcelin et al. (19) observed that when a dipeptidyl peptidase IVresistant analog of GLP-1 (GLP-1-Gly8) was tested in vivo, a single injection of $0.1 \mathrm{nmol}$ of the peptide in diabetic mice was capable of correcting fasting hyperglycemia and glucose intolerance for several hours. This was in contrast to the rapid disappearance of the peptide from the blood stream. Indeed, euglycemia was maintained over a period longer than could be predicted based on the peptide half-life (21). Furthermore, in a recently published study from our laboratory (22), we also observed that the capability of GLP-1 to induce the expression of the insulin transcription factor, IDX1 , starts increasing 2-3 days after the discontinuation of the treatment with GLP-1, and reaches its peak after almost a week, when the exogenous peptide has already been fully degraded. Because IDX-1 is a main transcription factor regulating the gene expression of insulin, glucose transporter GLUT-2 and glucokinase,
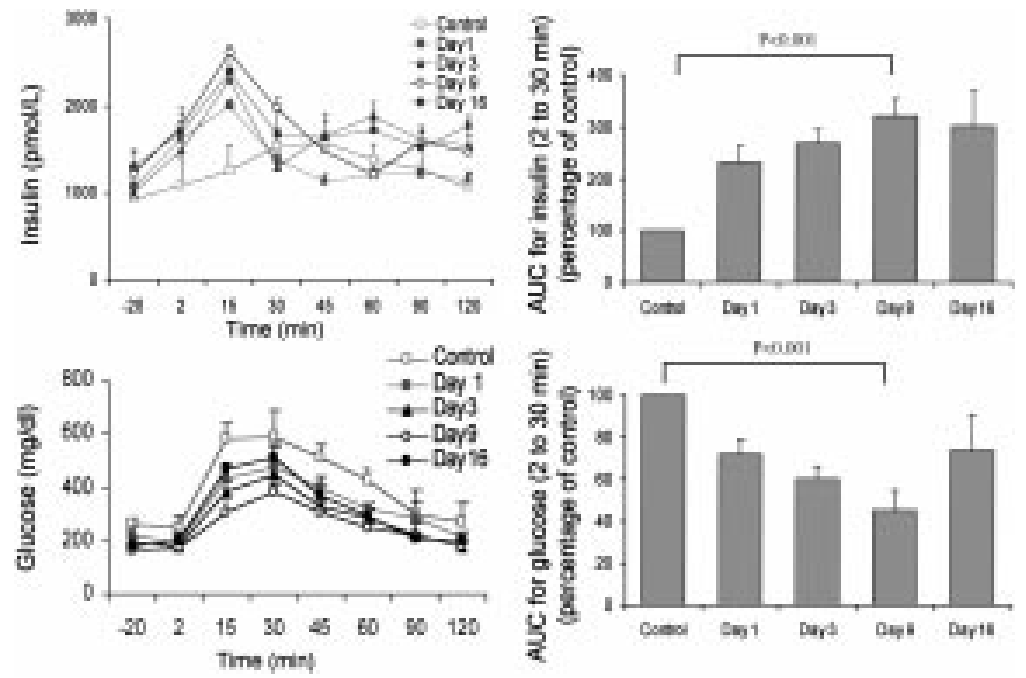

Figure 4 Long-lasting insulin secretory memory after GLP-1 infusion in ZDF rats. ZDF rats were subjected to a 2 day infusion with GLP-1 (30 pmol/kg per min) or saline solution and subjected to repeated IPGTTs (1 g/kg body weight) $1,3,9$ and 16 days after the discontinuation of GLP-1 infusion. Graphs on the left show glucose (lower) and insulin (upper) responses to repetitive IPGTT, while bar graphs on the right represent the AUCs for glucose (lower) and insulin (upper) from 0 to $30 \mathrm{~min}$ from the beginning of the glucose infusion. Means \pm S.E., $n=6$. Statistical significance was evaluated by Student's $t$-test. 
Table 1 Changes in body weight (means \pm S.E., $n=6$ ) in GLP-1- and saline-treated rats.

\begin{tabular}{lllcccc}
\hline & & \multicolumn{3}{c}{ Body weight $(\mathrm{g})$} \\
\cline { 3 - 7 } Rats & Treatment & $\begin{array}{c}\text { Before GLP-1 infusion } \\
\text { (day 0) }\end{array}$ & $\begin{array}{c}\text { After first IPGTT } \\
\text { (day 1) }\end{array}$ & $\begin{array}{c}\text { After second IGPTT } \\
\text { (day 3) }\end{array}$ & $\begin{array}{c}\text { After third IGPTT } \\
\text { (day 9) }\end{array}$ & $\begin{array}{c}\text { After fourth IGPTT } \\
\text { (day 16) }\end{array}$ \\
\hline ZDF & Saline & $452 \pm 29$ & $455 \pm 31$ & $457 \pm 41$ & $449 \pm 37$ & $446 \pm 46(\mathrm{~N} . \mathrm{S}$.) \\
ZDF & GLP-1 & $456 \pm 32$ & $450 \pm 27$ & $423 \pm 34$ & $370 \pm 22$ & $380 \pm 35(P<0.001)$ \\
ZLC & Saline & $155 \pm 17$ & $154 \pm 22$ & $160 \pm 30$ & $157 \pm 19$ & $161 \pm 16(\mathrm{~N} . \mathrm{S}$.) \\
ZLC & GLP-1 & $152 \pm 20$ & $145 \pm 24$ & $137 \pm 32$ & $132 \pm 15$ & $134 \pm 21(P<0.05)$ \\
\hline
\end{tabular}

Statistical significance was evaluated by unpaired Student's $t$-test (before GLP-1 infusion vs after fourth IPGTT).

the observation of a lasting effect of GLP-1, reported in the present study, may reflect the time course necessary for GLP-1 to exert its effect on the transcription of key regulator genes for $\beta$-cell function.

In attempting to explain the diverse effects of GLP-1 in vivo, we propose that this peptide hormone might act via different signaling pathways activated in a timedependent manner. In the first few minutes after its exogenous administration (acute phase) GLP-1 promotes a glucose-dependent secretion of insulin that is regulated via a cAMP/protein kinase A-dependent signaling pathway. This leads to the closure of the ATPsensitive potassium channels and to the activation of the sulfonylurea receptor SUR1. The closure of these channels results in a rise in the resting potential (depolarization) of the $\beta$-cell, leading to the opening of the voltage-sensitive calcium channels (L-type VDCC). The open-end L-type VDCC would then trigger the fusion of insulin-containing vesicles with the cell membrane resulting in the exocytosis of insulin (10). This phase lasts a few minutes and is the major target for the design of GLP-1 analogs.

The second phase of action of GLP-1 takes place within a few hours from the infusion of GLP-1 and is

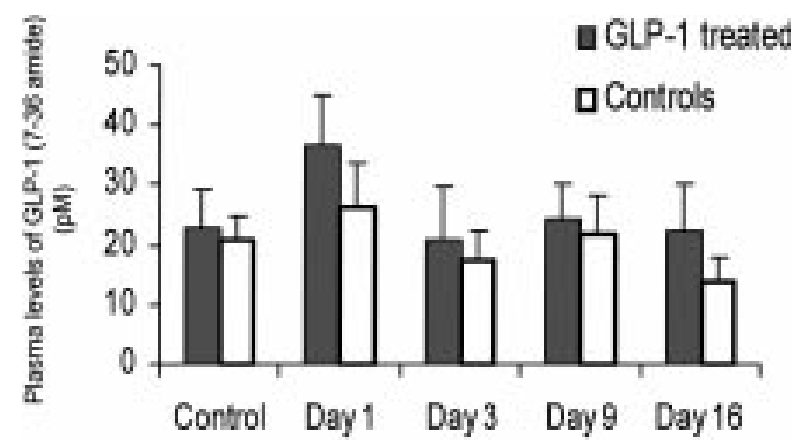

Figure 5 GLP-1 levels (means \pm S.E., $n=6$ ) in ZDF rats exposed to a 2 day infusion with human GLP-1. ZDF rats were subjected to a 2 day infusion with GLP-1 (30 pmol/kg per min) and their fasting GLP-1 levels measured on day 0 (prior to the exogenous infusion of GLP-1), day 1 (from the discontinuation of the GLP-1 infusion), 3, 9 and 16. The blood samples assayed to determine the levels of GLP-1(6-36) amide were collected $20 \mathrm{~min}$ before the IPGTT performed on the various testing days. characterized by the expression of $\beta$-cell-specific genes. These include insulin, GLUT-2 and the enzyme glucokinase. It has been proposed that in glucose-intolerant aging Wistar rats, this would result in a greater amount of insulin being synthesized and stored in the $\beta$-cells, leading to an overall improvement of glucose tolerance. It could also be attributed to the inhibitory effect of GLP-1 on gastric acid secretion and gastric emptying (14). In the hours after the exposure to GLP-1, its effects on the central nervous system also take place. Indeed, the brain is a very important target for GLP-1, as demonstrated by the observation that after infusion with radiolabeled GLP-1, approximately $9 \%$ (of the blood value) is found in the brain tissue (14). Interestingly, the capability of exogenously administered GLP-1 receptor agonists to reduce food intake and lower body weight is preserved in animal models of diabetes and obesity $(23-25)$. This observation has been confirmed in humans (in the presence or absence of diabetes), where the reduction in food intake has been interpreted as a satiety effect and not food aversion $(26,27)$.

The third phase of action of GLP-1 begins several days after the discontinuation of its administration and occurs when the active peptide is completely metabolized. This is probably regulated by the neogenesis and differentiation of $\beta$-cell triggered during the first phase, which results in an increase in $\beta$-cell mass, as demonstrated by recent reports from our and other laboratories (22).

In summary, the data presented in this report demonstrate that GLP-1, despite its short half-life, has a long-term effect in an animal model of type 2 diabetes.

\section{Acknowledgements}

This study was supported, in part, by the Foundation for Diabetes Research and by the American Federation for Aging Research. We would like to thank Olga Garcia for her technical support in the preparation of the manuscript. 


\section{References}

1 Holst JJ. Glucagon-like peptide-1 (GLP-1) a newly discovered GI hormone. Gastroenterology 1994107 1848-1855.

2 Fehmann HC, Goke R \& Goke B. Cell and molecular biology of the incretin hormones glucagon-like peptide- 1 and glucose-dependent insulin releasing polypeptide. Endocrine Reviews $1995 \mathbf{1 6}$ $390-410$

3 Drucker DJ. The glucagon-like peptides. Endocrinology 2001142 521-527.

4 Nauck MA, Heimesaat MM, Orskov C, Holst JJ, Ebert R \& Creutzfeldt W. Preserved incretin activity of glucagon-like peptide-1 [7-36 amide] but not synthetic human gastric inhibitory polypeptide in patients with type 2 diabetes mellitus. Journal of Clinical Investigation 199391 301-307.

5 Gutniak M, Orskov C, Holst JJ, Ahren B \& Efendic S. Antidiabetogenic effect of glucagon-like peptide-1 (7-36) amide in normal subjects and patients with diabetes mellitus. New England Journal of Medicine 1992326 1316-1322.

6 Nauck MA, Heimesaat MM, Orskov C, Holst JJ, Ebert R \& Creutzfeldt W. Normalization of fasting hyperglycemia by exogenous glucagon-like peptide-1 [7-36 amide] in type 2 (non-insulin dependent) diabetic patients. Diabetologia 199336 741-744.

7 Vilsboll T, Krarup T, Deacon CF, Madsbad S \& Holst JJ. Reduced postprandial concentrations of intact biologically active glucagon-like peptide 1 in type 2 diabetic patients. Diabetes $2001 \mathbf{5 0}$ 609-613.

8 Orskov C. Glucagon-like peptide-1, a new hormone of the enteroinsular axis. Diabetologia 1992107 1848-1855.

9 Ritzel R, Schulte M, Porksen N, Nauck MS, Holst JJ. Juhl C et al. Glucagon-like peptide 1 increases secretory burst mass of pulsatile insulin secretion in patients with type 2 diabetes and impaired glucose tolerance. Diabetes $200150776-784$.

10 Deacon CF, Johnsen AH \& Holst JJ. Degradation of glucagon-like peptide- 1 by human plasma in vitro yields an N-terminally truncated peptide that is a major endogenous metabolite in vivo. Journal of Clinical Endocrinology and Metabolism $1995 \mathbf{8 0}$ 952-957.

11 Oshima I, Hirota M, Ohboshi C \& Shima K. Comparison of halfdisappearance times, distribution volumes and metabolic clearance rates of exogenous glucagon-like peptide 1 and glucagon in rats. Regulatory Peptides 199821 85-93.

12 Siegel EG, Gallwitz B, Scharf G, Mentlein R, Morys-Wortmann C, Fölsch UR et al. Biological activity of GLP-1-analogues with N-terminal modifications. Regulatory Peptides 1999 79 93-102.

13 Knudsen LB \& Pridal L. Glucagon-like peptide-1-(9-36) amide is a major metabolite of glucagon-like peptide-1-(7-36) amide after in vivo administration to dogs, and it acts as an antagonist on the pancreatic receptor. European Journal of Pharmacology $1996 \mathbf{3 1 8}$ $429-435$.

14 Hassan M, Eskilsson A, Nilsson C, Jonsson C, Jacobsson H, Refai E et al. In vivo dynamic distribution of ${ }^{131} \mathrm{I}$-glucagon-like peptide-1 (7-36) amide in the rat studied by gamma camera. Nuclear Medicine and Biology $19994413-420$.

15 Ritzel R, Orskov C, Holst JJ \& Nauck MA. Pharmacokinetic, insulinotropic and glucagonostatic properties of GLP-1 (7-36 amide) after subcutaneous injection in healthy volunteers. Dose-response relationships. Diabetologia 199538 720-725.

16 Ahren B \& Pacinic G. Dose-related effects of GLP-1 on insulin secretion, insulin sensitivity, and glucose effectiveness in mice. American Journal of Physiology 1999277 E996-E1004.

17 Wang Y, Perfetti R, Greig NH, Holloway HW, DeOre KA, Montrose-Rafizadeh C et al. Glucagon-like peptide-1 can reverse the age-related decline in glucose tolerance in rats. Journal of Clinical Investigation 199799 2883-2889.

18 De Ore K, Greig NH, Holloway HW, Wang Y, Perfetti R \& Egan JM. The effects of GLP-1 on insulin release in young and old rats in the fasting state and during an intravenous glucose tolerance test. Journal of Gerontology 1997 52A B245-B249.

19 Burcelin R, Dolci W \& Thorens B. Long-lasting antidiabetic effect of a dipeptidyl peptidase IV-resistant analog of glucagon-like peptide-1. Metabolism $1999 \mathbf{4 8} 252-258$.

20 Sreenan SK, Mittal AA, Dralyuk F, Pugh WL, Polonsky KS \& Roe MW. Glucagon-like peptide-1 stimulates insulin secretion by a $\mathrm{Ca}^{2+}$-independent mechanism in Zucker diabetic fatty rat islets of Langerhans. Metabolism: Clinical and Experimental 200049 1579-1587.

21 Young AA, Gedulin BR, Bhavsar S, Bodkin N, Jodka C, Hansen B et al. Glucose-lowering and insulin-sensitizing actions of exendin-4: studies in obese diabetic $(\mathrm{ob} / \mathrm{ob}, \mathrm{db} / \mathrm{db})$ mice, diabetic fatty Zucker rats, and diabetic rhesus monkeys (Macaca mulatta). Diabetes 199948 1026-1034.

22 Perfetti R, Zhou J, Doyle ME \& Egan JM. GLP-1 induces cell proliferation, PDX-1 expression and increases endocrine cell mass in the pancreas of old, glucose intolerant rats. Endocrinology $20001414600-4605$.

23 Rodriquez de Fonseca F, Navarro M, Alvarez E, Roncero I, Chowen JA, Maestre $\mathrm{O}$ et al. Peripheral versus central effects of glucagonlike peptide-1 receptor agonists on satiety and body weight loss in Zucker obese rats. Metabolism: Clinical and Experimental 200049 709-717.

24 Szayna M, Doyle ME, Betkey JA, Holloway HW, Spencer RG, Greig $\mathrm{NH}$ et al. Exendin-4 decelerates food intake, weight gain, and fat deposition in Zucker rats. Endocrinology 2000141 1936-1941.

25 Davis HR Jr, Mullins DE, Pines JM, Hoos LM, France CF, Compton DS et al. Effect of chronic central administration of glucagon-like peptide-1 (7-36) amide on food consumption and body weight in normal and obese rats. Obesity Research 19986 147-156.

26 Flint A, Raben A, Astrup A \& Holst JJ. Glucagon-like peptide 1 promoters satiety and suppresses energy intake in humans. Journal of Clinical Investigation 1998101 515-520.

27 Gutzwiller JP, Drewe J, Goke B, Schmidt H, Rohrer B, Lareida J et al. Glucagon-like peptide 1 promotes satiety and reduces food intake in patients with diabetes mellitus type 2. American Journal of Physiology 1999276 R1541-R1544.

Received 15 October 2001

Accepted 11 March 2002 